\title{
SYNTHESIS AND CHARACTERIZATION OF SN DOPED CDO THIN FILMS BY NOVEL ADVANCED SPRAY PYROLYSIS TECHNIQUE
}

\author{
C. R. Bobade \\ Department of Physics, Balwant College, Vita; Dist. Sangli 415 311, (M.S.)India. \\ Email ID: chandrakant.bobade24@gmail.com, Contact-9503847031
}

\begin{abstract}
:
Polycrystalline Tin-doped Cadmium Oxide ( $\mathrm{Sn}: \mathrm{CdO})$ thin films were deposited onto glass at low substrate temperature of $210^{\circ} \mathrm{C}$ using advanced spray pyrolysis (ASP) technique. Sn doping (2-4 at\%) was achieved by using stannic chloride $\left(\mathrm{SnCl}_{4} .5 \mathrm{H}_{2} \mathrm{O}\right)$ used as a precursor. The films were grown at optimized preparative parameters. Effect of 'Sn' doping on the physical, electrical and optical properties of the films has been investigated. X-ray diffraction (XRD) studies show that films thus prepared are polycrystalline and have a rock salt type cubic crystal structure with preferential orientation along (111) plane. Field emission scanning electron microscopy (FESEM) micrographs show granular surface morphology and the average grain size was found to be around $152 \mathrm{~nm}$. Moreover it was seen that the small grains are aggregated to form big grains/structures. In particular, the $4 \% \mathrm{Sn}$ doped samples revealed a unique kind of triangular flower-like structured grain morphology. X-ray photoelectron spectroscopy (XPS) analysis indicated 'Sn' doping; while it was found from Energy Dispersive X-ray Analysis (EDAX) the extent of doping concentration and composition of the as-prepared films. A drastic increase in transmittance was seen for $4 \% \mathrm{Sn}$ doped $\mathrm{CdO}$ thin films as compared to other concentrations of Sn doping in CdO thin films. Semiconducting behavior of resistivity with temperature was observed. The resistivity was found to increase with increase in 'Sn' doping in CdO matrix.

Key words: Tin-doped Cadmium Oxide; Advanced spray pyrolysis technique; surface morphology, FESEM.
\end{abstract}

\section{INTRODUCTION:}

1.1 Today, one of the most important and commercially valued field of research in thin films has been recognized as the field of transparent conducting oxide (TCO) for the reasons that they have potential applications in flat-panel displays, architectural windows as well as electro-chromic windows, thin-film photovoltaics, gas sensors, etc [1-4]. TCOs especially, zinc oxide $(\mathrm{ZnO})$, cadmium oxide $(\mathrm{CdO})$, indium tin oxide (ITO), tin oxide $\left(\mathrm{SnO}_{2}\right)$ and other semiconducting oxide thin films, generally, have n-type semiconducting properties with relatively high-transparency in the visible-region. Moreover, they even have very low electrical resistivity obtained at optimized deposition conditions. However, an important issue in these TCOs is that the optical transparency and electrical resistivity are coupled with each other, wherein if the former increases the later decreases and viceversa. To achieve high quality concern with both the aforementioned properties of TCOs remains a challenge and hence rigorous research is taking place so as to achieve good quality TCO samples for considering them into advanced device applications [4-8].

1.2 Several different deposition techniques have been utilized in which chemical bath deposition (CBD) [9], thermal oxidation [10], sol-gel [11], pulsed laser deposition (PLD) [12] and spray pyrolysis (SP) [6, 13-15] have been utilized to synthesize different semiconducting oxide thin films. Amongst these techniques, the spray pyrolysis (SP) method seems to be the most competent considering its simplicity, cost effectiveness and good producibility on a large scale compared to other techniques [16]. In $\mathrm{SP}$ process, a precursor solution is pulverized using air or neutral gas that helps the very fine droplets to arrive at the preheated substrates. The precursor ionic solution starts to undergo chemical reaction on to the hot substrates to form the desired chemical compound on top of the heated substrate. As a matter of fact the substrate temperature forms a key parameter in SP technique, which thereby determines the physical and chemical properties of the as-deposited compound. 
1.3 So far, many researchers have studied physical, optical, and other properties of undoped and doped $\mathrm{CdO}$ thin films grown by SP. In these reports, mostly, CdO films were deposited on amorphous glass substrates above $400{ }^{\circ} \mathrm{C}[7,17]$ substrate temperature. The requirement of high substrate limits the use of conventional SP technique. The advanced/modified SP technique is designed to obtain good quality thin films for device fabrications at relatively lower substrate temperature. Moreover, it is augmented to an arrangement to rotate substrates, so as to obtain films of uniform thickness. Additionally, an appropriate exhaust mechanism is designed to reduce the exposure of toxic gases that causes health problems. Importantly, the mechanism of thin film formation is retained in the advanced spray pyrolysis technique (ASP). The pyrolytic reaction occurs in reaction chamber maintained at decomposition temperature of material and the final product gets deposited onto the substrates, kept at relatively low temperature. Here, the substrate temperature assists the nucleation/growth process. In this technique, the 'core temperature' as well as 'substrate temperature' is important parameters that influence film properties such as thickness, phase, crystallinity, etc. Hence, these parameters need to be optimized carefully to achieve good quality films with adequate properties.

1.4 The present investigation reports on synthesis of $\mathrm{Sn}: \mathrm{CdO}$ thin films onto glass substrate at low substrate temperature via aqueous route using ASP technique at pre- optimized parameters. As synthesized films exhibit good crystallinity, granular morphology at sufficiently low thickness resulting into large surface to volume ratio and can play a vital role in applications such as gas sensing. Henceforth we denote the $\mathrm{CdO}$ films deposited at 'Sn' doping concentration of 2, 3, and 4 at $\%$ as $\mathrm{S} 2, \mathrm{~S} 3$ and $\mathrm{S} 4$, respectively.

\subsection{Experimental set up}

The ASP system [18] is shown in figure. 1. It comprises of a furnace enclosed inside air tight wooden chamber. The top of furnace is fitted with substrate holder connected to a motor that can be rotated at a desired speed so as to obtain uniform thin films. Substrate holder is surrounded by a substrate heater coil connected to an a.c. supply. The substrate heater can heat the substrates up to 400 oC. Similarly, the furnace is surrounded by another heater coil and a temperature up to $900{ }^{\circ} \mathrm{C}$ can be attained inside the core of furnace having cross section $160 \times 160 \mathrm{~mm}^{2}$. Temperatures of both the furnace and substrate heater are controlled by PID type temperature controllers having an accuracy of $\pm 5{ }^{\circ} \mathrm{C}$ fitted to wooden chamber as shown. A glass nozzle fitted at the bottom of furnace is connected to a solution holder and 1 H.P. compressor via separate flow meters that assist to pulverize the precursor solution into fine atomized droplets inside the core of furnace where they undergo pyrolytic decomposition. The nozzle to substrate distance is adjustable.

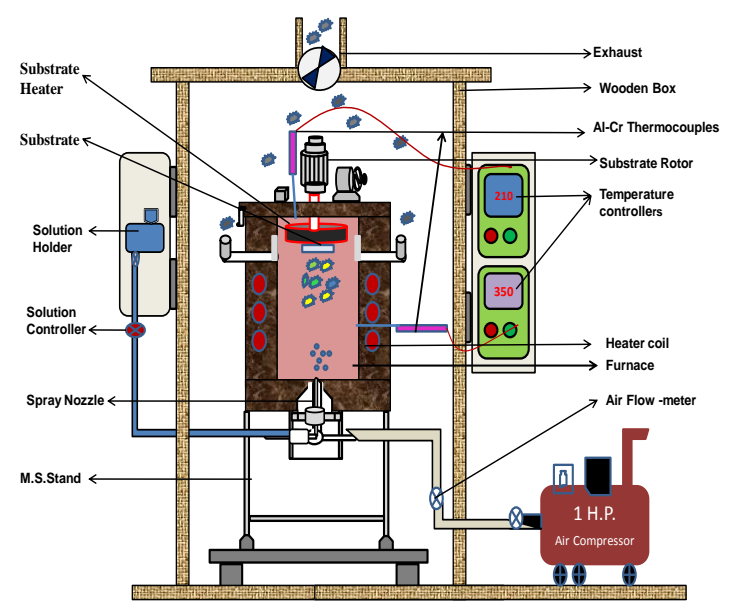

Fig.1. The advanced spray pyrolysis set-up[27]

\subsection{Synthesis of Sn:CdO thin films}

Tin doped $\mathrm{CdO}$ thin films were synthesized using advanced spray pyrolysis technique. A $0.02 \mathrm{M}$ aqueous solution $(300 \mathrm{ml})$ of high purity cadmium acetate $\left(\mathrm{Cd} \quad\left(\mathrm{CH}_{3} \mathrm{COO}\right)_{2} . \quad 2 \mathrm{H}_{2} \mathrm{O}\right)$ 
(Thomas Baker, India) dissolved in double distilled water (DDW) and doped with $\mathrm{Sn}$ at 2 to 4 at. \% was used to prepare Sn: CdO films. Sn doping 2 to 4 at \% is achieved by dissolving stannic chloride penta-hydrate $\left(\mathrm{SnCl}_{4} .5 \mathrm{H}_{2} \mathrm{O}\right)$ (Thomas Baker, India) in DDW. The solution was atomized through a glass nozzle and the reactants undergo pyrolytic decomposition in the reaction chamber of furnace to form deposition of oxide particles onto glass substrates. During the course of deposition, compressed air at a pressure of 10 LPM was forced to control the solution spray rate at $\sim 6 \mathrm{ml} / \mathrm{min}$. To study the effect of Sn doping on the CdO film properties, films were deposited onto glass slides $(75 \mathrm{~mm} x$ $25 \mathrm{~mm} \times 1.35 \mathrm{~mm})$ kept at constant substrate temperature $210{ }^{\circ} \mathrm{C}$. Deokate et al. [17] reported that the acetate group can be removed in the temperature range from 235 to $315{ }^{\circ} \mathrm{C}$ from cadmium acetate dehydrate precursor to get a stable CdO phase; hence, the core temperature where the actual decomposition occurs was optimized at constant at $325{ }^{\circ} \mathrm{C}$ after repetitive trials. The substrate to nozzle distance was optimized to be $41 \mathrm{~cm}$.

\subsection{Characterization of Sn:CdO thin films}

The crystalline structure and phase formation of the Sn:CdO films was characterized using X-ray diffractometer (XRD) [Bruker D-2 Phaser, Powder XRD made by analytical instruments Pvt. Ltd., Germany] in the scanning range of 20$80^{\circ}$ at a step size of 0.1 . The $\mathrm{Cu} K_{a}(\lambda=1.5406$ A) radiation was used. Film surface morphology and thickness was studied by field emission scanning electron microscopy (FESEM) [FESEM, Nova NanoSEM 200]. The thickness of the $\mathrm{Sn}: \mathrm{CdO}$ film was confirmed by surface profiler. Transmittance was measured by using UV-VISNIR spectrophotometer (made by Schimadzu, Japan) in the range 300-900nm.

\section{Results and Discussion}

Structural and Morphological Studies of Sn:CdO thin films

\subsubsection{X-ray diffraction analysis}

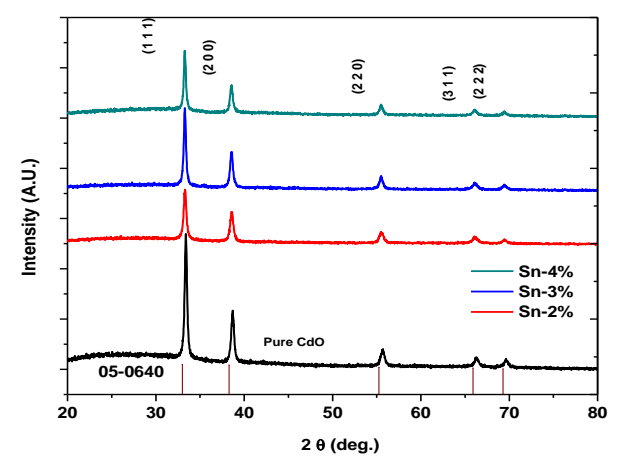

Fig.2. XRD patterns of undoped and Sn doped CdO thin films[27]

The effect of doping concentration on the crystalline state of the films was studied using XRD. Fig. 2 shows the XRD patterns of films grown at different doping concentrations. It is evident from the figure that crystallographic property of the Sn: CdO films depend on level of doping. Films were polycrystalline in nature showing (1 11 1), (2 0 0), (2 $\left.2 \begin{array}{ll}2 & 0\end{array}\right),\left(\begin{array}{lll}3 & 1 & 1\end{array}\right)$ and (2 2 2) planes and were highly oriented along (111) plane. The observed'd' values were in good agreement with those reported in the JCPDS card (No. 05-0640), indicating that the films are cubic in nature. It was observed from XRD patterns that there is a slight shift in the diffraction angles to higher side. It was observed that the intensity of diffracted peak increases with increase in doping level from sample S2 to S4. It was also seen that with 'Sn' doping the intensity of (111) peak enhanced, while the other peaks remained almost constant. This indicates that one can grow strongly oriented films along a particular plane direction using such a technique. Further, we calculated the crystallite size by using standard DebyeScherrer formula [19] given by,

$$
D=\frac{0.9 \lambda}{\beta \cos \theta_{B}}
$$

Where, $\mathrm{D}=$ particle size, $\theta_{B}=$ diffraction angle, $\lambda$ =wavelength of $\mathrm{X}$-rays and $\beta=$ line broadening at Full Width at Half Maxima (FWHM). It was 
observed that with 'Sn' doping in $\mathrm{CdO}$ the crystallite size [calculated for (111) plane] enhanced after initially remaining constant.

Fig. 3 (a-d) shows the FESEM micrographs for pure $\mathrm{CdO}, \mathrm{S}_{2}, \mathrm{~S}_{3}$ and $\mathrm{S}_{4}$ samples, respectively. FESEM micrographs show that the film surface is granular in nature, and tiny crystallites/grains have coalesced together to form larger crystallites/grains. Apart from this, pure $\mathrm{CdO}, \mathrm{S}_{2}$ and $\mathrm{S}_{3}$ films surfaces have compact morphology [see Fig. 3 (a-c), respectively]; while less compact morphology with triangular flower-like structures (Fig. 3d) was observed in case of $\mathrm{S}_{4}$ sample. It is suggested that for gas sensing properties, compact granular morphology has less sensing behavior than porous natured morphology. Hence, in our case sample $\mathrm{S}_{4}$ could possibly show good gas sensing properties

EDAX studies carried out for a typical sample is shown in fig. 4 (a). Elements $\mathrm{Sn}, \mathrm{Cd}$, and $\mathrm{O}$ were detected in the S3 sample which ensured 'Sn' doping in the $\mathrm{CdO}$ matrix. The atomic percentage as obtained for $\mathrm{Sn}$ : $\mathrm{Cd}: \mathrm{O}$ was 2.93: $38.40: 58.5 \%$, respectively, which was found to be comparable with the initial atomic percentage taken while preparing the precursor solutions. Higher percentage of oxygen is attributed to contributions from glass substrate. Elemental mapping of the same S3 sample was carried out using EDAX, and the representative element images are shown in figures 4(b), (c) and (d). Figures 4(b), (c) and (d), show presence of $\mathrm{Cd}$, $\mathrm{Sn}$ and O, respectively. Observation of film surface confirmed that the 'Sn' was properly doped into the CdO matrix.

\subsection{Optical Studies}

The optical band gap is calculated from the absorbance spectra for different samples using the absorption coefficient ' $a$ ' and photon energy $(\mathrm{h} \square)$ as given by the relation [20],

$$
\alpha=A \frac{\left(h v-E_{g}\right)^{n}}{h v}
$$

where, ' $\mathrm{E}_{\mathrm{g}}$ ' is the band gap energy, ' $\mathrm{hv}$ ' is the photon energy, ' $\mathrm{n}$ ' is constant and is equal to $1 / 2$ or $3 / 2$ depending on whether transition is allowed or forbidden and $\mathrm{A}$ is a constant. For allowed and direct transitions $n=1 / 2$. Thus by plotting (ahv) ${ }^{2}$ against hv, the band gap energy ' $\mathrm{E}_{\mathrm{g}}$ ' is determined by extrapolating the linear portion of the curve to the energy axis at $a=0$.

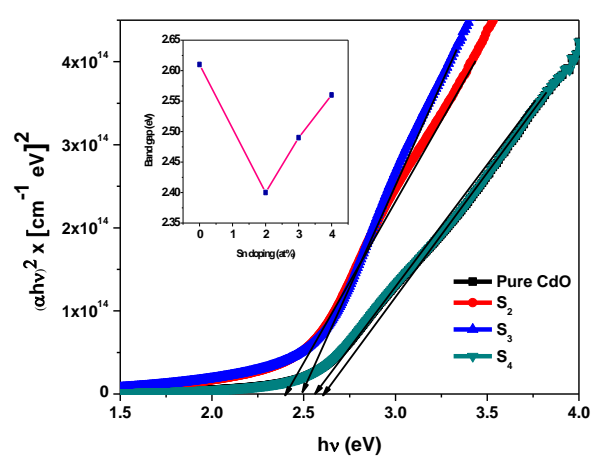

Fig.5. : Plots of $a h v^{2} v s$. hu for undoped and $S n$ doped CdO films.

[inset: Plot indicates variation in band gap with doping concentration.][27]

Fig. 5. shows that the direct band gap energy of pure $\mathrm{CdO}$ is $2.60 \mathrm{eV}$ and it is in good agreement with the value reported by other researchers [21]. The band gap values calculated for $\mathrm{S}_{2}, \mathrm{~S}_{3}$ and $\mathrm{S}_{4}$ is found out to be $2.41,2.46$ and $2.58 \mathrm{eV}$, respectively. It is observed that the band gap of doped CdO films is less than the pure CdO thin film [see inset of Fig. 5]. However, blue shift was observed with increase in ' $\mathrm{Sn}$ ' doping concentration [22]. This might be related to a phenomenon known as the Burstein-Moss (BM) effect [23, 24]. It has been analyzed and found out that a wide band gap is appreciated for transparent conducting oxides in most potential applications $[22,25,26]$. CdO being a transparent conducting oxide, is not that popular as compared to other transparent conducting oxides such as $\mathrm{SnO}_{2}, \mathrm{ZnO}$, etc. due to its low band gap values. Here in our case the increasing trend of the band gap with increase 
in the 'Sn' concentration in $\mathrm{CdO}$ might be useful for potential applications.

\section{CONCLUSION:}

It is possible to synthesize $\mathrm{Sn}$ doped $\mathrm{CdO}$ thin films at low substrate temperature using advanced spray pyrolysis technique. The structural and optical properties were seen to be strongly dependent on 'Sn' doping concentration. Pure $\mathrm{CdO}$ and $\mathrm{Sn}$ doped $\mathrm{CdO}$ thin films were found to have polycrystalline nature It was also seen that with 'Sn' doping the (111) peak got strongly enhanced, while the intensity of other peaks remained almost constant indicating that one can grow highly oriented films along a preferred direction using advanced spray pyrolysis technique. The films grown at low substrate temperature and at different doping concentrations have size of the order of few nanometers. The film deposited at 3 at \% Sn doping $\left(\mathrm{S}_{3}\right)$ is highly oriented along (111) plane and exhibits good crystallinity. FESEM analysis of CdO films support the XRD analysis and confirm that the films are polycrystalline having granular morphology and could be useful for gas sensing applications. Optical properties show that films are transparent to visible light, with a direct band gap $\sim 2.4-2.6 \mathrm{eV}$.

\section{REFRENCES:}

H. M. Ali, Phys. Status Solidi A 202 (2005) 2742.

H. M. Ali, H. A. Mohamed, M. M. Wakkad, and M. F. Hasaneen, Japanese J. Appl. Phys. 48 (2009) 041104.

B. Saha, R. Thapa, and K. K. Chattopadhyay, Solid State Commun. 145 (2008) 33.

M. Kul, A. S. Aybek, E. Turan, M. Zor, and S. Irmak, Sol. Energy Mater. Sol. Cells 91 (2007) 1927.

J. Tores, J.I. Cisseneros, G. Gordillo, F.Alvarez, Thin Solid Films 289 (1996) 238.

K.L. Chopra, S. Major, D.K. Pandey, Thin Solid Films 102 (1983) 1.

C. H. Bhosale, A.V. Kambale, A.V. Kokate, K.Y. Rajpure, Mater. Sci. \& Eng. B 122 (2005) 67-71.
P. Cowache, D. Lincot, J. Vedd, Electrochem. Soc. 139 (1989) 67.

R.R. Salunkhe, D.S. Dhawale, U.M.Patil, C.D.Lokhande, Sens. Actuators B: Chem. 136 (2009) 39-44.

C. Dantus, G. G. Rusu, m. Dobromir, M. Rusu, Appl. Surf. Sci. 255 (2008) 2665-2670.

M. Benhaliliba, C.E. Benouis, A. Tiburcio-Silver, F. Yakuphanoglu, A. Avila-Garcia, a. Tavira, R. R. Trujillo, Z. Mouffak, J. Luminescence 132 (2012) 2653-2658.

B.J. Zeng, J.S. Lian, L. Zhao, Q. Jiang, Vacuum 85 (2011) 861-865; R.K. Gupta, K. Ghosh, R. Patel, P.K. Kohol, Appl. Surf. Sci. 255 (2009) 6252-6255.

R. Kumaravel, K. Ramamurthi, J. Phys. Chem. Solids (2010) 1545-1549.

M.K.R. Khan, M. Azizar Rahman, M. Shahjahan, M, Mozibur Rahman, M. A. Hakim, Current Applied Physics 10 (2010) 790796.

R. Ferro, J. A. Rodriguez, Thin Solid Films 347 (1999) 295-298.

P. S. Patil, Mater. Chem. Phys. 59 (1999) 185198.

R. J. Deokate, S. M. Pawar, A. V. Moholkar, V. S. Sawant, C. A. Pawar, C. H. Bhosale, K. Y. Rajpure, Applied Surface Science 254 (2008) 2187-2195.

P. S. Shewale, S. I. Patil and M.D. Uplane, Semiconductor Science and Technology, 25 (2010) 115008 (6pp).

B. D. Cullity, Elements of X-ray Diffraction, Second ed., Addison-Wesley, Reading MA, (1978) 162.

D. Kim, S. Kim, Surf. Coat.Technol.176 (2003) 23.

B. Saha, S. Das, K. K. Chattopadhyay, Solar Energy Materials \& Solar Cells 91 (2007) 1692-1697.

A. A. Dakhel, Journal of Mater. Sci. 46 (2011) 1455; A. A. Dakhel, Journal of Alloys Compd. 475 (2009) 51; X. Wu, T. J. 
Coutts, W. P. Mulligan, J. Vac. Sci. Technol. A 15 (1997) 1057.

E. Burstein Phys Rev 93 (1954) 632.

T. S. Moss Proc Phys Soc London B 67 (1954) 775.

T. J. Coutts, D. L. Young, X. Li, MRS Bull. 25 (2000) 58.
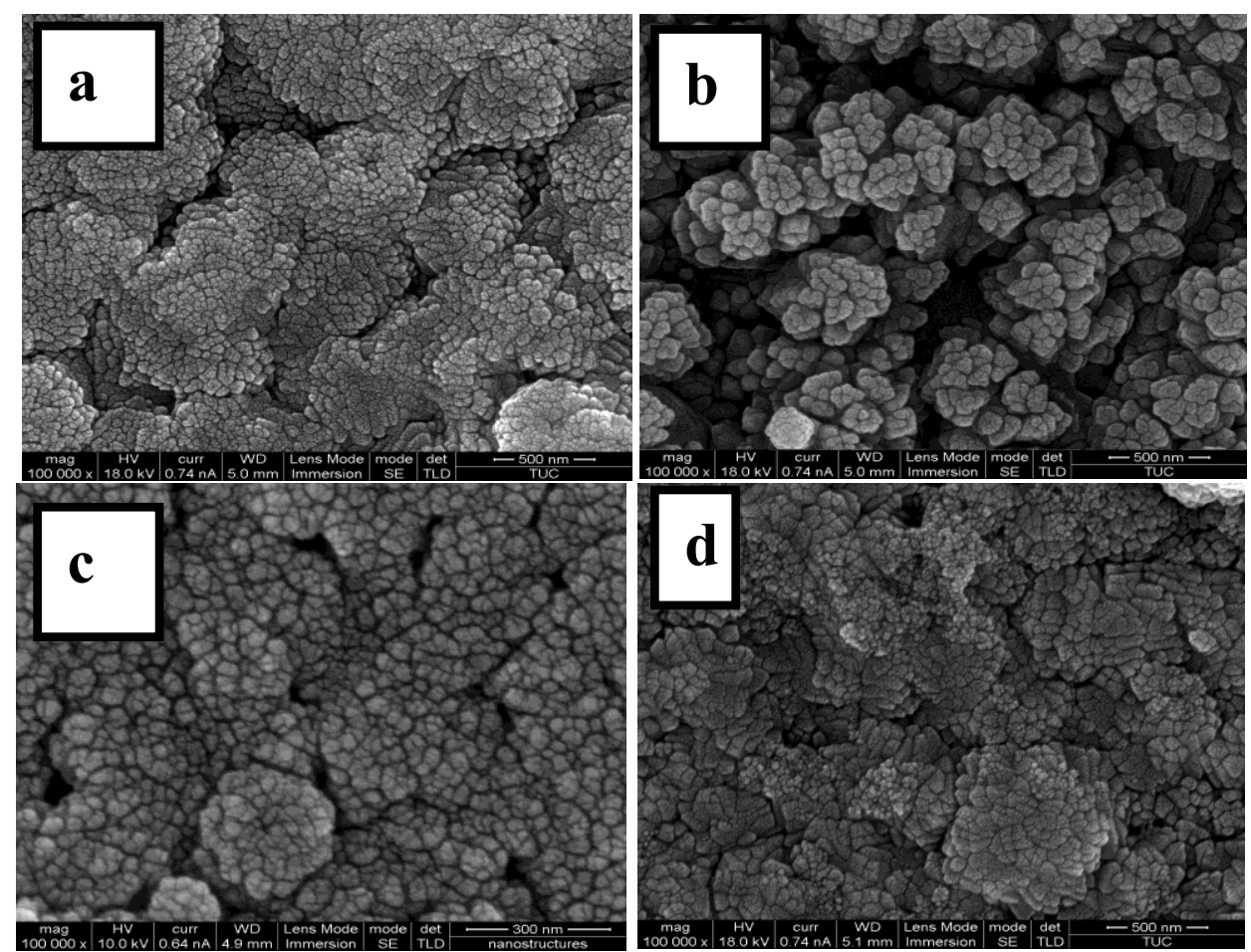

Fig.3. Plain view FESEM micrographs a) for pure $C d O$ b) for sample $S_{2}$ c) for sample $S_{3} \quad \& d$ ) for sample $S_{4}$ [27] 


\section{EDAX analysis}

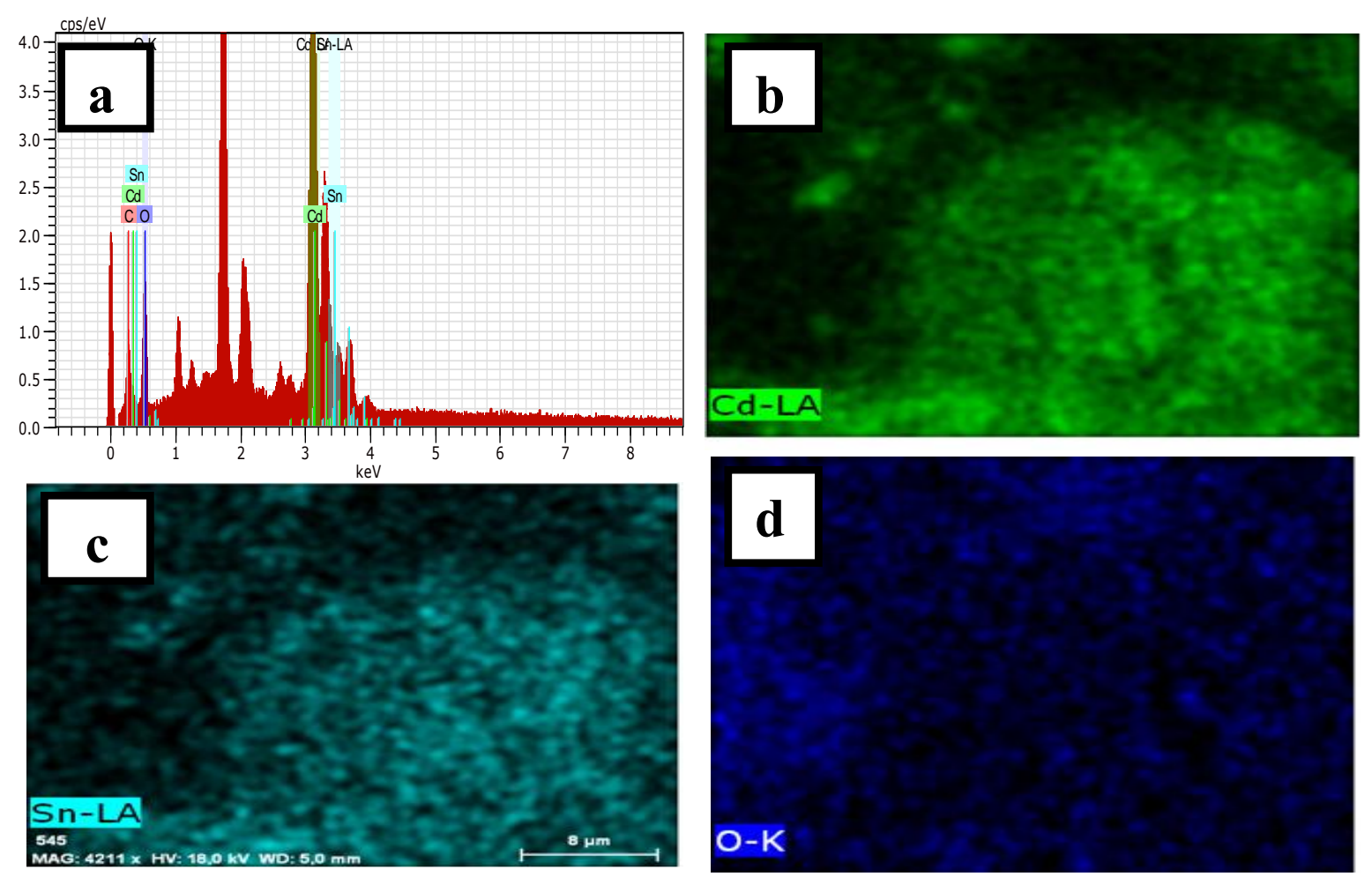

Fig.4. EDAX analysis [27] 